\title{
AERODYNAMIC PERFORMANCE AND FLOW-FIELD CHARACTERISTICS OF TWO WAVERIDER-DERIVED HYPERSONIC CRUISE CONFIGURATIONS
}

\author{
Charles E. Cockrell, Jr.* and Lawrence D. Huebner ${ }^{\dagger}$ \\ NASA Langley Research Center, Hampton, VA \\ Dennis B. Finley** \\ Lockheed-Fort Worth Company, Fort Worth, TX
}

\begin{abstract}
$\underline{\text { Abstract }}$
The component integration of a class of hypersonic high-lift configurations known as waveriders into hypersonic cruise vehicles was evaluated. A wind-tunnel model was developed which integrates realistic vehicle components with two waverider shapes, referred to as the "straight-wing" and "cranked-wing" shapes. Both shapes were conical-flowderived waveriders for a design Mach number of 4.0. Experimental data and limited computational fluid dynamics (CFD) predictions were obtained over a Mach number range of 1.6 to 4.63 at a Reynolds number of $2.0 \times 10^{6}$ per foot. The CFD predictions and flow visualization data confirmed the shock attachment characteristics of the baseline waverider shapes and illustrated the waverider flow-field properties. Experimental data showed that no significant performance degradations, in terms of maximum lift-to-drag ratios, occur at offdesign Mach numbers for the waverider shapes and the integrated configurations. A comparison of the fully-integrated waverider vehicles to the baseline shapes showed that the performance was significantly degraded when all of the components were added to the waveriders, with the most significant degradation resulting from aftbody closure and the addition of control surfaces. Both fully-integrated configurations were longitudinally unstable over the Mach number range studied with the selected center of gravity location and for unpowered conditions. The cranked-wing configuration provided better lateral-directional stability characteristics than the straight-wing configuration.
\end{abstract}

\section{$\underline{\text { Nomenclature }}$}

$\mathrm{C}_{\mathrm{D}} \quad$ Drag coefficient

$\mathrm{C}_{1} \quad$ Rolling moment coefficient

$\mathrm{C}_{1 \beta} \quad$ Rolling moment derivative

$\mathrm{C}_{\mathrm{L}} \quad$ Lift Coefficient

$\mathrm{C}_{\mathrm{m}} \quad$ Pitching moment coefficient

$\mathrm{C}_{\mathrm{n}} \quad$ Yawing moment coefficient

$\mathrm{C}_{\mathrm{n} \beta} \quad$ Yawing moment derivative

D Drag (lbf)

L Lift (lbf)

M Mach number

$\mathrm{p} \quad$ Static pressure $\left(\mathrm{lbf} / \mathrm{ft}^{2}\right)$

Re Reynolds number

$\mathrm{S}_{\text {ref }} \quad$ Planform area $\left(\mathrm{ft}^{2}\right)$

\footnotetext{
* Aerospace Engineer, Hypersonic Airbreathing Propulsion Branch, Gas Dynamics Division, Member AIAA.

† Aerospace Engineer, Hypersonic Airbreathing Propulsion Branch, Gas Dynamics Division, Senior Member AIAA.

** Engineering Group Specialist, Senior Member AIAA.
}

\author{
$\mathrm{T} \quad$ Temperature $\left({ }^{\circ} \mathrm{R}\right)$ \\ $\mathrm{V} \quad$ Total volume $\left(\mathrm{ft}^{3}\right)$ \\ $\mathrm{V}_{\text {eff }} \quad$ Volumetric efficiency $\left(\mathrm{V}^{2 / 3} / \mathrm{S}_{\mathrm{ref}}\right)$ \\ $\mathrm{X}, \mathrm{Y}, \mathrm{Z} \quad$ Cartesian coordinates \\ $\alpha \quad$ Angle of attack (deg) \\ $\beta \quad$ Sideslip angle (deg) \\ $\xi, \eta, \zeta \quad$ Computational coordinates
}

\section{Subscripts \\ $\infty \quad$ Freestream quantity \\ w Wall quantity (temperature) \\ Introduction}

A waverider is any shape that is designed such that the bow shock generated by the shape is perfectly attached along the outer leading edge at the design condition. The waverider design method leads to several advantages over conventional hypersonic concepts. The attached leading edge shock wave confines the high pressure region to the lower surface and results in high lift-to-drag ratios. Design predictions suggest that these lift-to-drag ratios are higher than conventional hypersonic concepts, giving waveriders an aerodynamic performance adavntage. The flow field below the waverider bottom surface is uniform and, in the case of waveriders derived from axisymmetric flow fields, there is little or no crossflow in this region, making these shapes attractive candidates for engine integration. These advantages have led to interest in using waverider shapes as the forebodies of hypersonic airbreathing engine-integrated airframes. Waveriders have been considered for various types of missions including hypersonic cruise vehicles, single-stage-to-orbit vehicles, airbreathing hypersonic missiles and various space-based missions. 1

A specific waverider shape is uniquely defined by freestream conditions, the type of generating flow-field body and a leading edge definition. ${ }^{2}$ The shapes of the upper and lower surfaces of the configuration follow from these parameters. The freestream conditions, including Mach number and Reynolds number or altitude, are selected based on mission criteria. The design method used in this study involves a specific design point. The generating flow-field body is used to define the shock shape upon which the leading edge of the waverider is constructed. Any arbitrary body in supersonic or hypersonic flow can be used as a generating flow-field body. This study focuses specifically on conical-flow-derived waveriders, where the generating flow-field body is a right circular cone in supersonic or hypersonic flow. The length of the generating cone, length of the waverider and semi-apex 
angle of the cone are specified by the designer. The selection of these parameters can have a significant effect on the shape of the waverider generated as well as on the aerodynamic performance of the configuration. Figure 1 illustrates the design of a conical-flow derived waverider. The planform shape, or leading edge, is defined on the shock wave produced by the cone. The lower surface of the configuration is defined by tracing streamlines from the leading edge to the base of the configuration. The result is that the lower compression surface is a stream surface behind the conical shock wave. The configurations studied here have an upper surface which is designed as a constant freestream pressure surface. However, other techniques may be used, such as shaping the upper surface as an expansion or compression surface. The conical flow field, defined behind the shock wave, exists only below the lower surface of the waverider.

The resulting configuration provides two distinct advantages over conventional hypersonic configurations. The first is an aerodynamic performance advantage over conventional vehicles. $^{2,3,4}$ Theoretically, the shock wave is perfectly attached along the outer leading edge at the design Mach number. The result is that the high pressure region behind the shock wave is confined to the lower surface and no flow spillage from the lower surface to the upper surface occurs. The maximum lift-to-drag ratios which are produced by this method are higher than those of conventional hypersonic concepts. ${ }^{4}$ Another advantage of axisymmetric waverider flow fields is that they provide excellent propulsion/ airframe integration (PAI) characteristics. ${ }^{5}$ The lower surface flow field is uniform and there is pure conical flow in this region for a perfectly attached shock wave. These characteristics are ideal for the integration of engine modules that require a high quality, compressed inlet flow, such as a scramjet. The aerodynamic performance and PAI benefits offered by waveriders have generated interest in their use for various hypersonic vehicle designs.

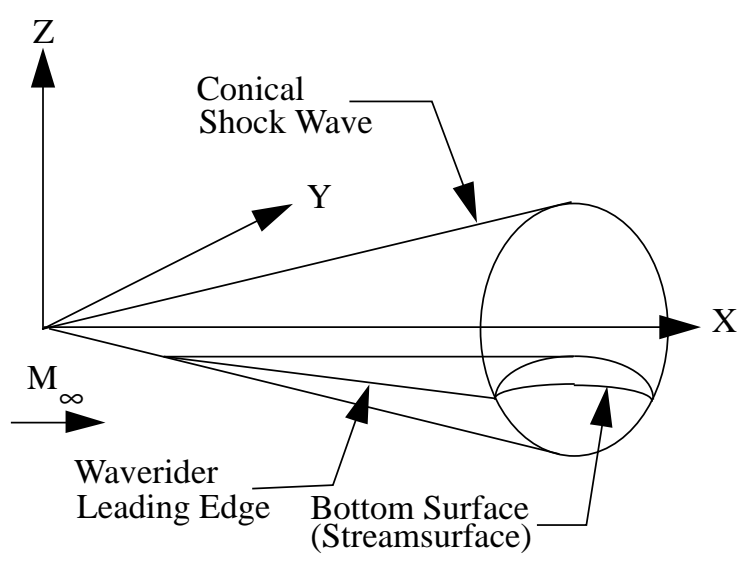

Figure 1. Waverider Designed From Conical Flow Field
The purpose of the current study was to examine the aerodynamic characteristics of two waverider-derived hypersonic cruise vehicles. Therefore, the objectives of this study were twofold. The first was to create an experimental and computational data base for waverider-derived configurations. The second was to examine the effects of individual vehicle components on pure waverider performance, to determine the differences in aerodynamic performance and stability which result from integrating all vehicle components and to assess whether the fully-integrated waverider-derived configuration provides the same advantages that the pure waverider does. No data currently exist which address the integration of realistic vehicle components with pure waverider shapes. The objectives of the study were accomplished using results from wind-tunnel testing and limited computational fluid dynamics (CFD) solutions. The CFD predictions were obtained for the baseline (pure) waverider shapes only. A wind-tunnel model was designed which integrated canopies, engine packages and control surfaces with two Mach 4.0 waverider configurations. Limited CFD predictions were obtained for the baseline waverider configurations in order to provide comparisons with experimental data and design-code predictions.

This paper contains a discussion of the methods used to select the two waverider shapes used as well as the development of the wind-tunnel model. The details of the experimental study are then presented as well as the computational method used to obtain the CFD predictions. The results are analyzed in three sections. First, the results of the baseline waverider configurations without integrated components are presented, including flow-field characteristics from CFD solutions and experimental flow visualization data as well as aerodynamic performance and stability data from the experiment and CFD predictions. Second, the experimental results of integrating aircraft components with the baseline waverider shapes are presented. The effects of the canopy, engine components and control surfaces on aerodynamic performance and stability are examined. Finally, the characteristics of the fully-integrated waverider-derived configurations are examined and compared to those of the baseline waverider shapes. The effectiveness of the control surfaces for pitch and lateral-directional control is not discussed in this paper.

\section{Waverider Forebody Description and Model Development}

The baseline waverider configurations used in this study were designed using the MAXWARP design code, developed at the University of Maryland. ${ }^{3}$ The freestream conditions and optimization parameters were chosen based on the applicability of this study to a hypersonic cruise vehicle, with ground-based test facility limitations taken into account. The design freestream Mach number was 4.0 and the design Reynolds number was $2.0 \times 10^{6}$ per foot. Although the specific Mach number range of interest for this type of vehicle would be approximately 5.0 to 5.5, Mach 4.0 was selected as the design point based on the limitations of available ground test facilities and the range of data desired. A design point of Mach 4.0 allowed for data to be obtained at, 
above and below the design point. This allowed for the validation of the waverider concept at the design Mach number and for the more complete evaluation of off-design performance. Data obtained in this range of Mach numbers would be applicable to a Mach 5.0-5.5 vehicle with only a re-design of the waverider forebody necessary in order to achieve shock attachment at the design point of interest. The Reynolds number was chosen based on nominal facility operating conditions and is not representative of a flight cruise altitude. Maximum lift-to-drag ratio was used as an optimization parameter since this is more appropriate as a hypersonic cruise performance parameter than minimum drag.

Two different waverider shapes were developed for this study. The first shape is referred to as the "straight-wing" shape and was designed using the optimization routine in MAXWARP. The second shape, referred to as the "crankedwing" shape, was created by adjusting the leading edge of the straight configuration to create a curved wing-tip shape that had increased aspect ratio, but still maintained shock attachment along the outer leading edge at the design freestream condition. The leading edge of the cranked-wing waverider was defined on the same conical shock wave as the straightwing shape. The term "cranked" in this context refers to a shape in which the sweep angle not only changes, but also has a large dihedral angle in the plane of the base. The crankedwing shape was designed to provide improvements in subsonic performance, due to an increase in the aspect ratio, and directional stability, while maintaining the waverider aerodynamic performance advantage in the supersonic/hypersonic regime.

Photographs of the straight-wing and cranked-wing pure waverider configurations are shown in figures 2 and 3, respectively. The lower surface of the straight-wing waverider has a slightly convex curvature in the cross section in order to facilitate addition of the propulsion system. Additionally, the lower surfaces of both configurations deviate slightly from the waverider streamsurface by having a slight expansion surface which begins approximately 2 inches upstream of the base (figure 4). Additional model volume was added by perturbing the shape of the freestream upper surface in order to accommodate the sting and balance necessary to measure aerodynamic loads on the model during testing. The waverider model was chosen to be 24 inches in length. The length of the generating cone was selected to be twice that of the waverider length. The selection of these parameters fixes the location of the waverider on the generating shock wave. The maximum lift-to-drag ratios predicted by the design code are 6.859 for the straight-wing model and 6.743 for the cranked-wing model. The generated shapes were judged to provide a significant aerodynamic performance advantage at the design Mach number, while possessing good volumetric and structural characteristics for a realistic hypersonic cruise vehicle. Additional details on the waverider shapes and model design are included in reference 6.

Canopies and propulsion systems components were designed for the waverider-based configurations. The first canopy was designed with faceted surfaces to resemble a real-

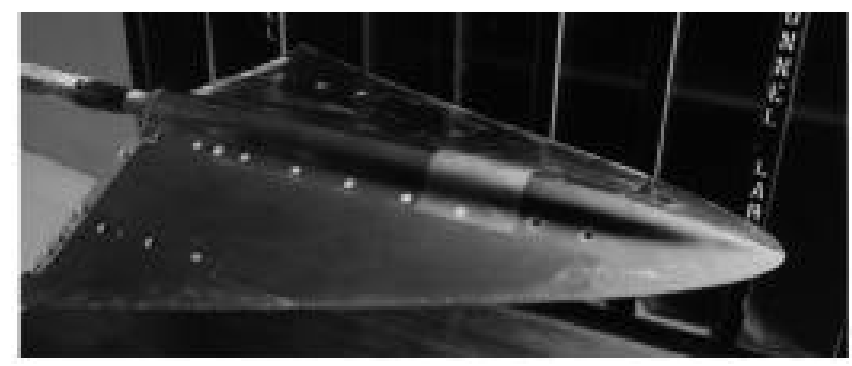

Figure 2. Photograph of baseline straight-wing waverider.

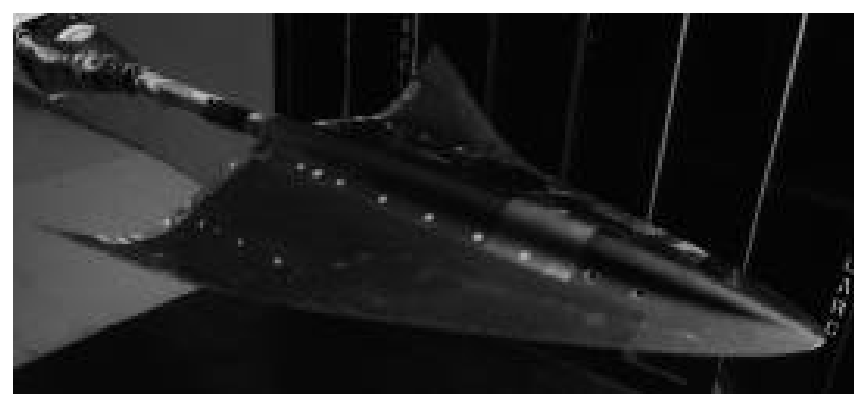

Figure 3. Photograph of baseline cranked-wing waverider.

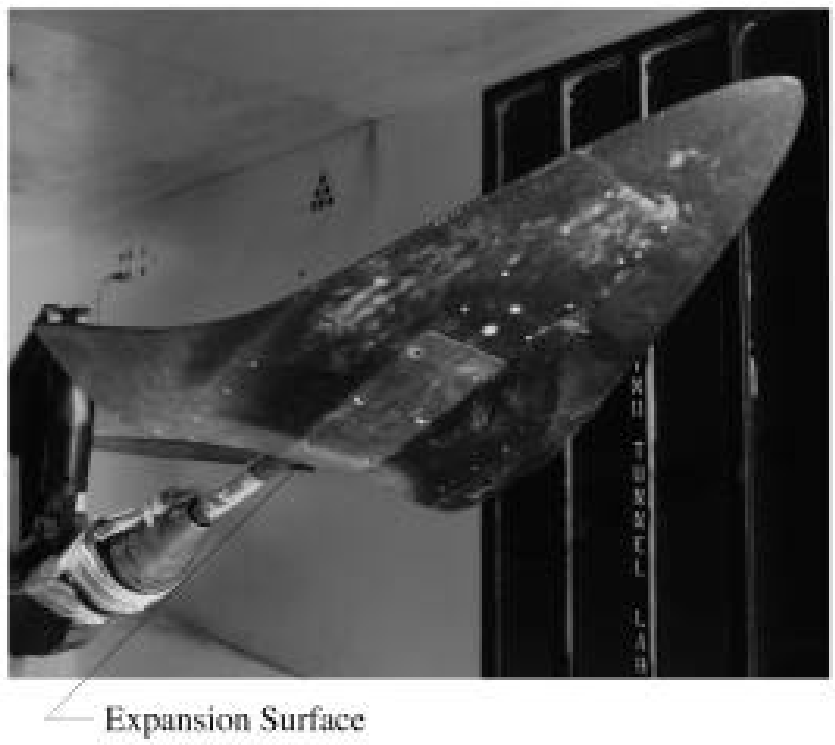

Figure 4. Photograph of baseline cranked-wing waverider lower surface.

istic canopy for a hypersonic vehicle. Because of the design of the model, a canopy-off configuration could not be tested. Therefore, a smooth ogive canopy was designed in order to provide a comparison of the aerodynamic performance between the two canopies. These canopies are referred to as the faceted and smooth canopies, respectively. Figures 2 and 3 show the model with the smooth canopy attached, while figures 5 and 6 show the faceted canopy attached to the model. The smooth canopy is also shown in figure 6. The engine package included an inlet and nozzle/expansion ramp, also shown in figure 5. The engine-on design was intended to provide an indication of the unpowered aerodynamic effect of modifying the waverider airframe to integrate a propulsion system and not to provide an accurate simulation of propul- 
sion effects. The inlet consisted of a compression ramp with two side walls. Two different nozzle/expansion ramps were designed, one for use with configurations that do not have control surfaces attached and the second for configurations which have control surfaces. These are referred to as the "short" and "long" nozzles, respectively. The inlet capture area, expansion ramp turning angle and nozzle exit area were designed for Mach 4.0 cruise conditions using industry design practices, propulsion data and estimated full-scale drag values. Identical nozzles with static pressure taps were also fabricated in order to obtain surface pressure measurements on the nozzle. The non-instrumented ramps were used when obtaining force and moment data.

Control surfaces were designed and fabricated in order to examine their effects on waverider aerodynamic performance as well as the effectiveness of the control concept. Figures 5 and 6 show the model with various control surfaces. The control surfaces were sized based on control-volume trends from supersonic fighter aircraft. The control surfaces close the blunt base of the configuration to a sharp trailing edge. Elevons were designed for angles of 0 , positive 20 (trailing edge down) and negative 20 (trailing edge up) degrees. Because of the severe closure angle and the method by which the control surfaces were attached to the waverider shape, different parts were fabricated for each fixed angle. A set of outboard ailerons for the same three angles was designed for the straight wing. Because of the curved surface of the cranked wing and the small thickness of the outer leading edge, the set of ailerons for the cranked-wing configuration consisted of an inboard aileron, which remained fixed at zero degrees, and a set of outboard ailerons, which were deflected at 0 , positive 20 and negative 20 degrees. A vertical tail surface was designed to augment directional stability. The model is 26.597 inches in length with control surfaces attached.

\section{Experimental Method}

The facility utilized in this study was the Unitary Plan Wind Tunnel (UPWT) at NASA Langley Research Center. ${ }^{7}$ The low-Mach-number test section has a Mach number range of 1.47 to 2.86 and the high-Mach-number test section has a range of 2.30 to 4.63 . Configurations tested ranged from the straight and cranked pure waverider shapes with no engines or control surfaces up to the fully-integrated waverider-derived vehicles with all components attached. Six component force and moment data were obtained over a Mach number range of 1.60 to 4.63 for the cranked-wing configurations and over a range of 2.30 to 4.63 for the straight-wing configurations. Flow visualization data, including schlieren and laser vapor-screen photographs, were taken over the same Mach number ranges. Static pressures were measured on the nozzle surface for selected conditions. Detailed run schedules are included in reference 6.

The balance utilized in this study was the NASALangley-designated UT-50-B balance. The accuracy of the this balance, based on an April 1993 calibration, is 0.5 percent of full-scale for each component to within 95 percent confidence. The full-scale load limits were: $600 \mathrm{lbf}$ normal,
$40 \mathrm{lbf}$ axial, 1500 in-lbf pitching moment, 400 in-lbf rolling moment, $800 \mathrm{in}-\mathrm{lbf}$ yawing moment and $300 \mathrm{lbf}$ side force. As an example, using the method of root-mean-squares summation to combine independent error sources, this corresponds to a range of uncertainty in lift coefficient of 0.0053 at $\alpha=0^{\circ}$ to 0.0054 at $\alpha=10^{\circ}$ and an uncertainty range in drag coefficient of 0.00036 at $\alpha=0^{\circ}$ to 0.001 at $\alpha=10^{\circ}$ for the $\mathrm{M}_{\infty}=4.0$ and $\mathrm{Re}_{\infty}=2.0 \times 10^{6}$ per foot condition. The repeatability of measurements in each test section was observed to be better than these uncertainties. Therefore, differences less than these ranges observed in comparisons of data from different configurations in the same test section could be considered significant. However, comparisons between independent measurements or measurements from different test sections are only good to within these uncertainty ranges.

\section{Computational Method}

Computational grids were developed for each of the pure waverider configurations by first developing a numerical surface description and then creating 3D volume grids. Numerical surface descriptions of the straight-wing and cranked-wing wind-tunnel models were obtained from CAD descriptions of the model parts. Three-dimensional volume grids were created for each configuration using the GRIDGEN software package, which utilizes algebraic transfinite interpolation methods with elliptic interior point refinement. ${ }^{8}$ Only the baseline waverider model with no integrated vehicle components was modeled in the CFD analysis.

The CFD solutions were obtained using the General Aerodynamic Simulation Program (GASP), version 2.2.9,10 GASP is a finite volume code capable of solving the full Reynolds-averaged Navier-Stokes (RANS) equations as well as subsets of these equations, including the parabolized NavierStokes (PNS), thin-layer Navier-Stokes (TLNS) and Euler equations. Time integration in GASP is based on the integration of primitive variables, and convergence to a steady state solution is obtained by iterating in pseudo-time until the L2 norm of the residual vector has been reduced by a sufficient amount. GASP also contains several flux-split algorithms and limiters to accelerate convergence to steady state. Mesh sequencing is also available as a means to accelerate convergence.

In this study each configuration was modeled as a two zone problem, as illustrated in figure 7. The first zone included the blunt nose of the configuration. The flow in this region is a combination of subsonic and supersonic flow since there will be a small area of subsonic flow behind the detached bow shock. Therefore, the TLNS equations were solved over the first zone using a global iteration procedure. The second zone encompassed the remainder of the configuration, extending from the zonal boundary to the base of the configuration. The flow in this region was computed by applying the PNS equations. These equations are valid for regions of predominately supersonic flow with no streamwise separation. A no-slip boundary condition was applied to all solid boundaries with a fixed wall temperature of $585{ }^{\circ} \mathrm{R}$, which is identical to that specified in the MAXWARP optimization routine when designing the waverider shapes. 


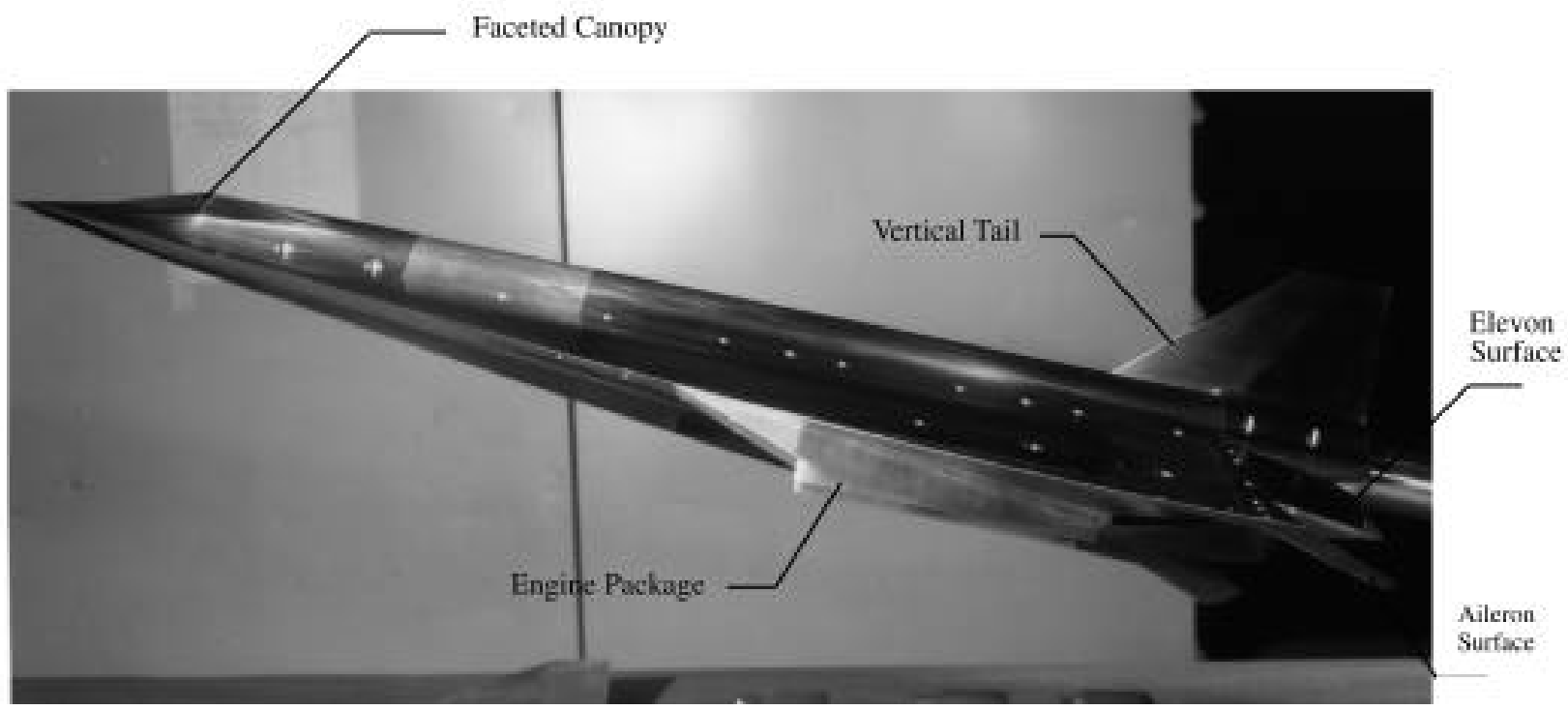

Figure 5. Photograph of straight-wing fully-integrated waverider model.

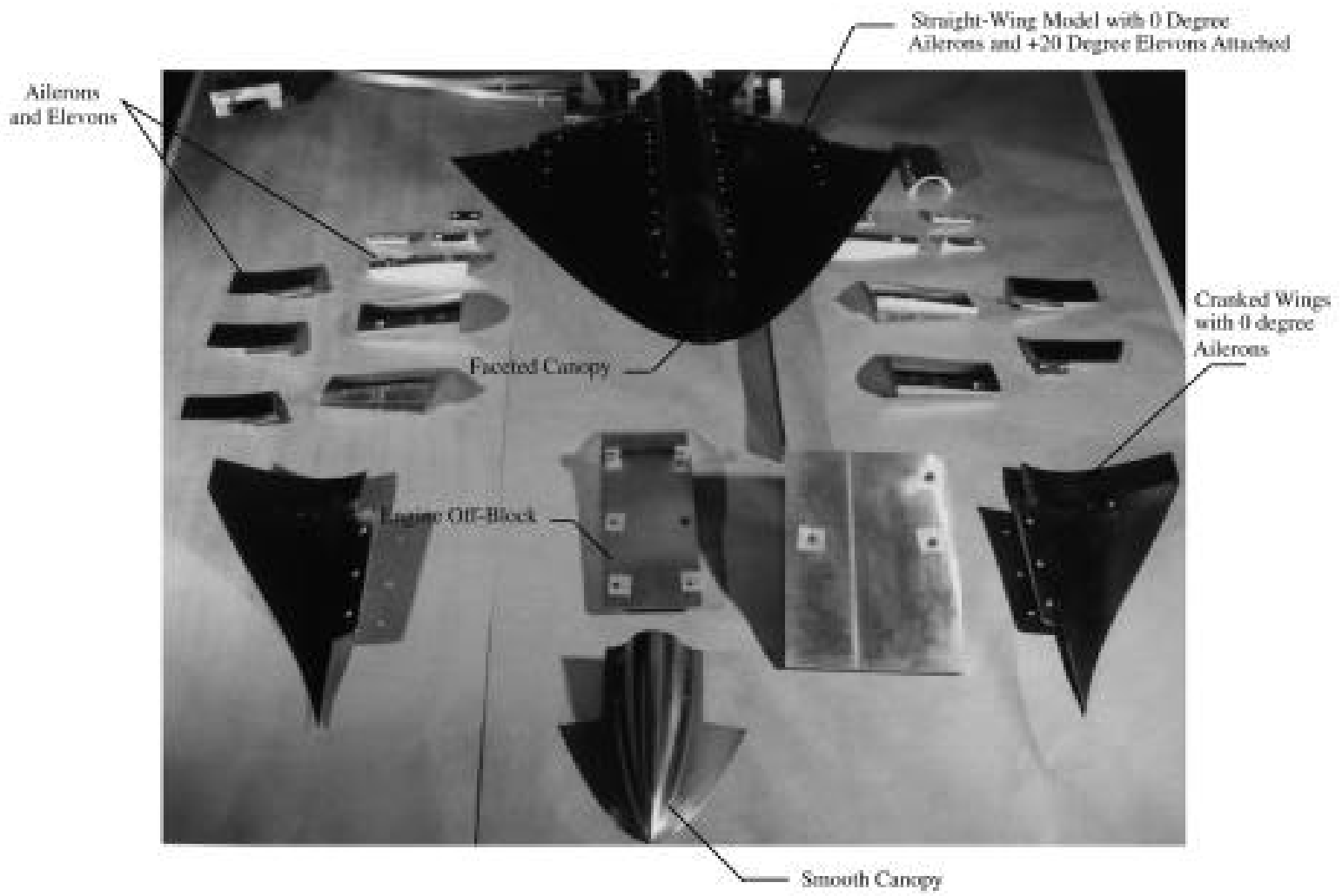

Figure 6. Photograph of waverider wind-tunnel model with various vehicle components. 


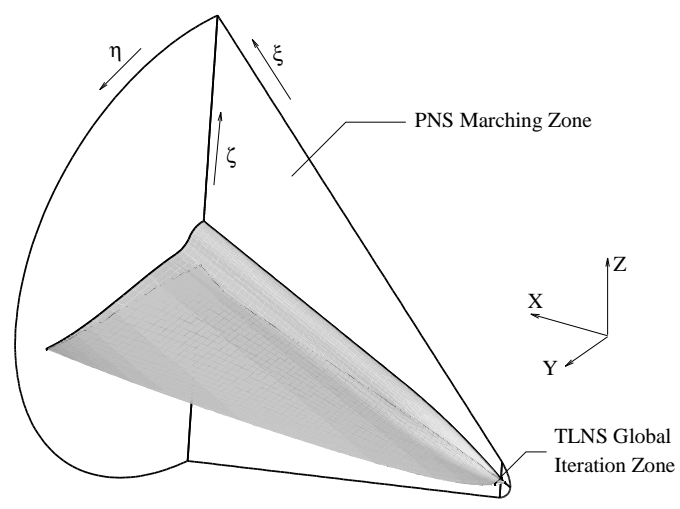

Figure 7. Coordinates and computational scheme for waverider CFD solutions.

Freestream conditions were applied at the outer boundary; second order extrapolation from interior cells was applied at the last streamwise plane and symmetry boundary conditions were applied on the center plane. The Baldwin-Lomax algebraic turbulence model was used in these solutions to model turbulent boundary layers, and convergence to a steady state was obtained by reducing the L 2 norm of the residual vector by 5 orders of magnitude.

\section{$\underline{\text { Results and Discussion }}$}

\section{Baseline Waverider Shapes}

The flow-field characteristics of each of the baseline pure waverider shapes can be examined using CFD solutions and experimental flow visualization data. Figure 8 shows a laser vapor-screen photograph of the flow at the base cross section of the straight-wing pure waverider model and nondimensional static pressure contours at the base cross section of the same configuration from a CFD solution at Mach 4.0, $0^{\circ}$ angle of attack and a freestream Reynolds number of $2.0 \times 10^{6}$ per foot. The photograph was taken using a camera mounted behind the model and looking upstream. The model lower surface is highlighted in the photograph by the laser light sheet on the surface. The bow shock is indicated by the contrast between light and dark regions below the light sheet. On the left-hand side of the photograph, the shock is observed to be very near the edge of the lower surface. Thus, the vaporscreen photograph confirms the qualitative shock location predicted by the CFD solution. A small detachment distance exists even at the design point due to blunt leading edge and boundary layer displacement effects. The experimental data and CFD predictions also indicate that the high pressure region remains confined below the model lower surface. A large low pressure region ( $\mathrm{P} / \mathrm{P}$ of 0.95 or less) exists near the center line of the model below the bottom surface due to the bottom surface expansion present on the model. However, the remainder of the bottom surface flow field is a smooth, conical flow field, so the presence of this slight expansion surface does not degrade the PAI characteristics of

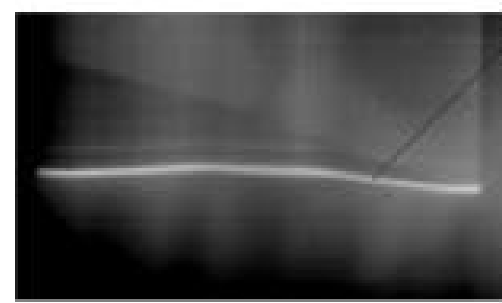

Lower

surface

Vapor Screen Photograph at Base

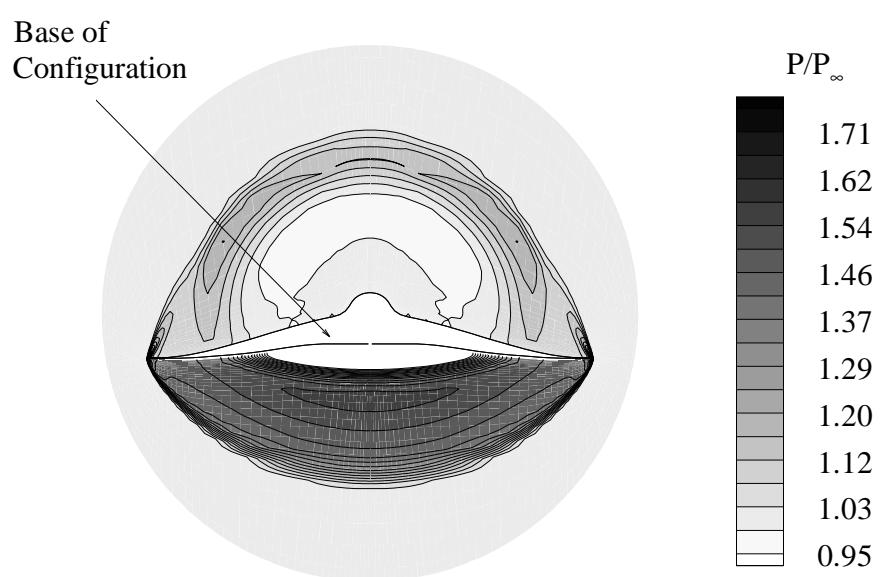

Base View of CFD Solution

Figure 8. Comparison of base-view vapor-screen photograph and non-dimensional static pressure contours from a CFD solution of the straight-wing model at Mach 4.0, $\alpha=0^{\circ}$.

the waverider. Engine modules would be placed upstream of the point where the expansion surface begins, so the flow entering the inlet would be highly compressed. Similar data are shown in figure 9 for the cranked-wing pure waverider model. The shock can be seen in the right-hand side of the photograph to be very near the outer leading edge of the model. The lower surface is again highlighted by the laser light. The experimental data confirm the qualitative shock location at the outer leading edge, which is predicted by the CFD solution for this case as well.

The lift-to-drag ratios for the cranked-wing and straight-wing pure waverider model are shown in figures 10 and 11. These figures show experimental data as well as predictions from CFD solutions and the MAXWARP design code. The CFD values were obtained by integrating surface pressure and skin friction predictions from CFD solutions. For both experiental and computational data, the data were corrected to assume that freestream pressure is acting at the blunt base. In other words, base drag is not included. This is also the manner in which the design code computes lift and drag values within the optimization routine. In general, there is good agreement between the CFD predictions and experimental data. Both the computational predictions and experimental data show lower lift-to-drag ratios than the designcode predictions. The flow visualization data and CFD flowfield solutions showed that a slight detachment distance exists 


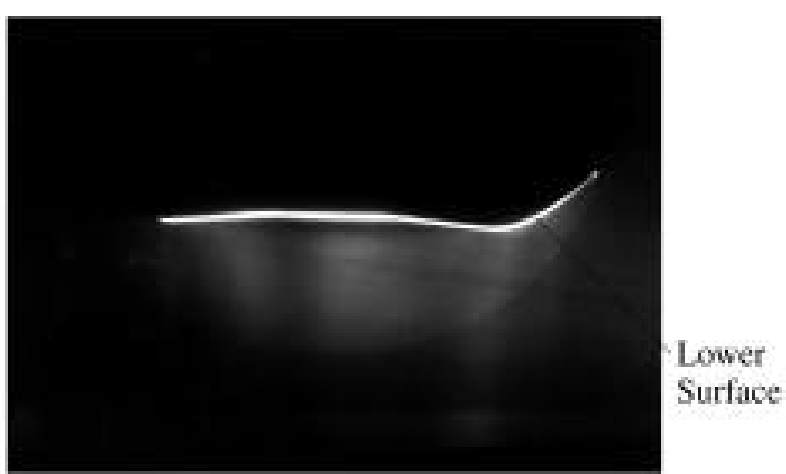

Vapor Screen Photograph at Base

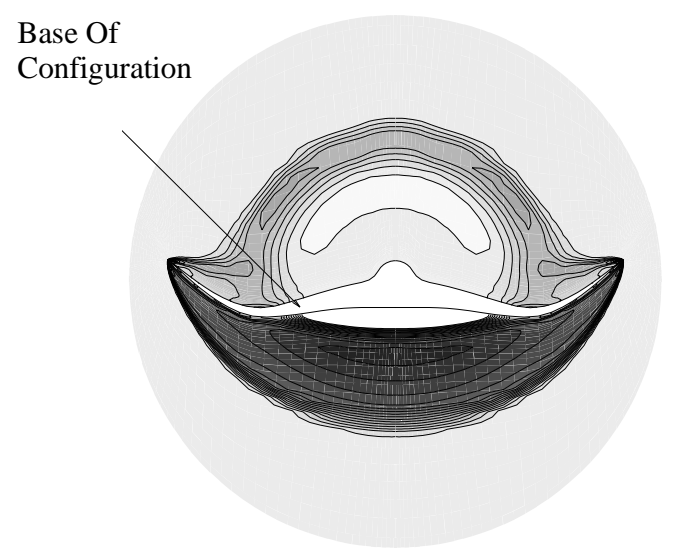

$\mathrm{P} / \mathrm{P}_{\infty}$

\section{Base View of CFD Solution}

Figure 9. Comparison of base-view vapor-screen photograph and non-dimensional static pressure contours from a CFD solution of the cranked-wing model at Mach 4.0, $\alpha=0^{\circ}$.

even at the design Mach number of 4.0. The resulting flow spillage leads to a slight lift loss and drag increase over the design code prediction, because the design code assumes an infinitely sharp leading edge with a perfectly attached shock wave. An additional lift loss results from the expansion on the model lower surface discussed previously and a drag increase results from the presence of the additional volume on the upper surface of the wind tunnel model. The experimental data also show that the maximum lift-to-drag ratio occurs near $2^{\mathrm{O}}$ angle of attack. The lateral flow spillage caused by shock detachment results in a lift loss and requires the model to be pitched at a higher angle of attack in order to achieve a comparable lift coefficient as the $0^{\circ}$ angle of attack, perfectly attached shock condition..

\section{Component Build-Up Effects}

The effects of each of the vehicle components on waverider aerodynamic performance are examined through comparisons of experimental data. The effects of the canopy, engine package and addition of $0^{\circ}$ control surfaces are analyzed. In this section, only data for the cranked-wing configuration at the design Mach number are presented for brevity. However, the effects on the straight-wing model and at off-

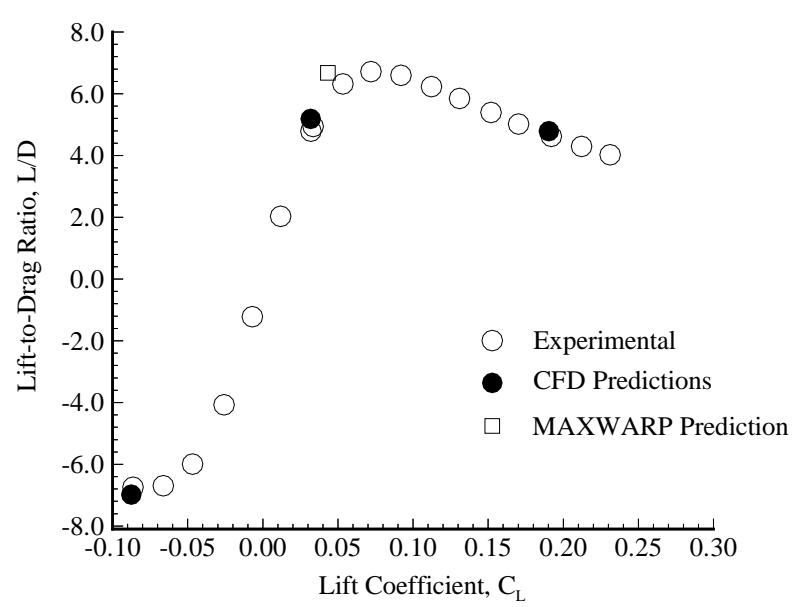

Figure 10. Comparison of experimental data, $\mathrm{CFD}$ and design predictions for the cranked-wing waverider at Mach 4.0.

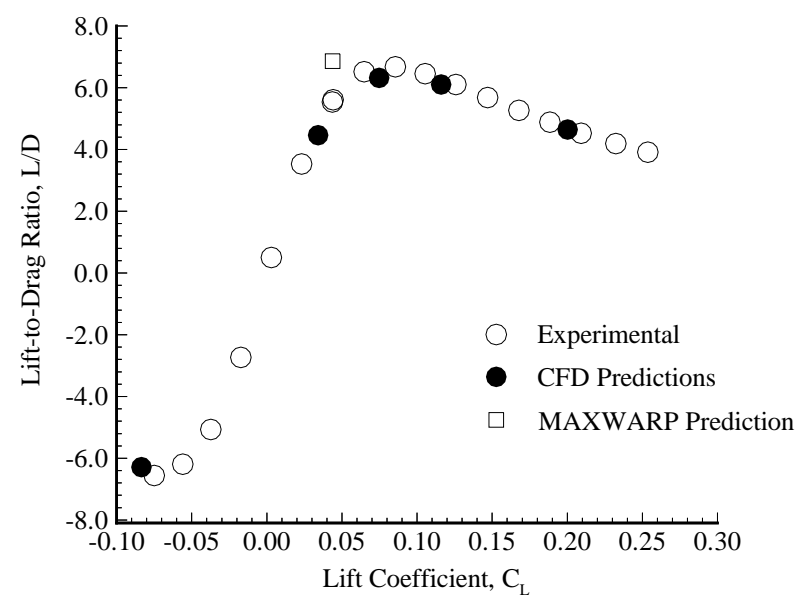

Figure 11. Comparison of experimental data, CFD and design predictions for the straight-wing waverider at Mach 4.0.

design conditions are similar in all cases. ${ }^{6}$

The effect on aerodynamic performance of adding the faceted canopy to the cranked-wing waverider is shown in figure 12. This figure shows lift-to-drag ratios at Mach 4.0 for the pure waverider model with the smooth canopy attached and the waverider with the faceted canopy attached, but no other vehicle components integrated. The data are again presented assuming freestream pressure acting at the blunt base. The experimental data indicate that there is a 5.1 percent reduction in maximum lift-to-drag ratio at Mach 4.0 for the cranked-wing configuration when the faceted canopy is used, as compared to the smooth canopy. For comparison, the data indicate a 3.6 percent reduction for the straight-wing configuration. This reduction in maximum $\mathrm{L} / \mathrm{D}$ is due primarily to a slight increase in drag between the faceted-canopy and the smooth-canopy configurations. Therefore, the analysis indicates that the primary effect of adding a realistic canopy is a slight degradation in aerodynamic performance. The faceted canopy is used in the remaining configurations studied. 
The effect on aerodynamic performance of adding the engine package to the cranked-wing waverider is shown in figure 13. Experimental lift-to-drag ratios are shown for both engine-off and engine-on configurations at Mach 4.0. Both configurations shown have the facted canopy and no control surfaces attached. The addition of engine components results in a 17.7 percent decrease in maximum lift-todrag ratio at Mach 4.0 for the cranked-wing configuration. For comparison, the straight-wing model shows a 19.7 percent reduction. These decreases are primarily due to a large increase in drag caused by the increase in projected frontal area. A slight increase in lift was also observed due to the inlet compression surface.

The effects of adding $0^{\circ}$ control surfaces are illustrated by comparing configurations with no control surface to those with $0^{\circ}$ elevons and $0^{\circ}$ ailerons attached. Note that the engine components are also attached to the configurations compared here. The effects of adding control surfaces on the cranked-wing waverider configuration are shown in figure 14 and 15 . Figure 14 shows a comparison of drag values at Mach 4.0 for controls-off and controls-on configurations. The coefficient data are reduced by the planform areas of each corresponding configuration so the effects of increased planform are accounted for in the normalization of these data. There is a significant increase in drag when the control surfaces are added. This is due primarily to the assumption of freestream pressure acting at the base in the controls-off case and a significant reduction in base area when the controls are added. In other words, a large increase in base drag results when the blunt base is eliminated by adding control surfaces. The base area is approximately 9.1 percent of the planform area for the cranked-wing controls-off case and approximately 0.82 percent for the controls-on case. For the straightwing model, the base area is 8.3 percent of the planform area for the controls-off case and 0.88 percent for the controls-on case. A slight lift loss also results from the addition of control surfaces due to the large expansion angle present on the elevon lower surface. These effects cause a significant reduction in lift-to-drag ratios at Mach 4.0, as shown in figure 15. The addition of control surfaces causes a 17.7 percent reduc-

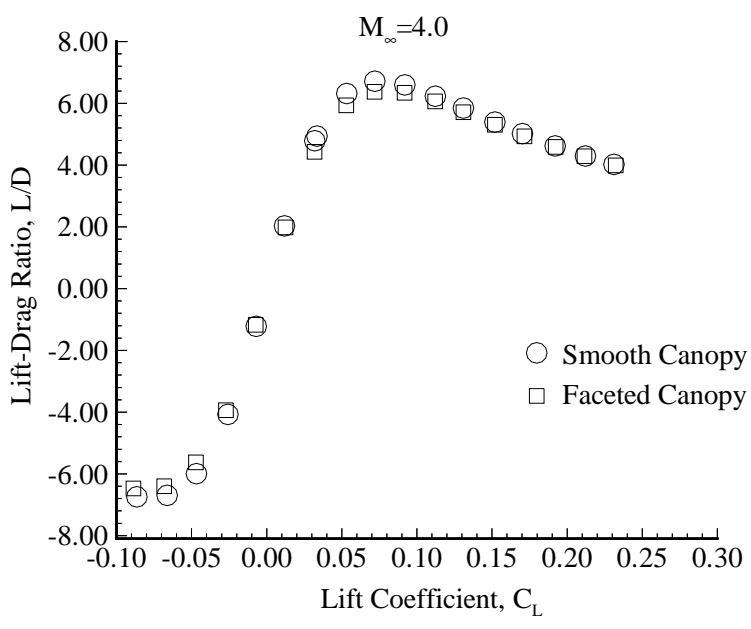

Figure 12. Effect of canopy on lift-to-drag ratios of cranked-wing waverider at Mach 4.0.

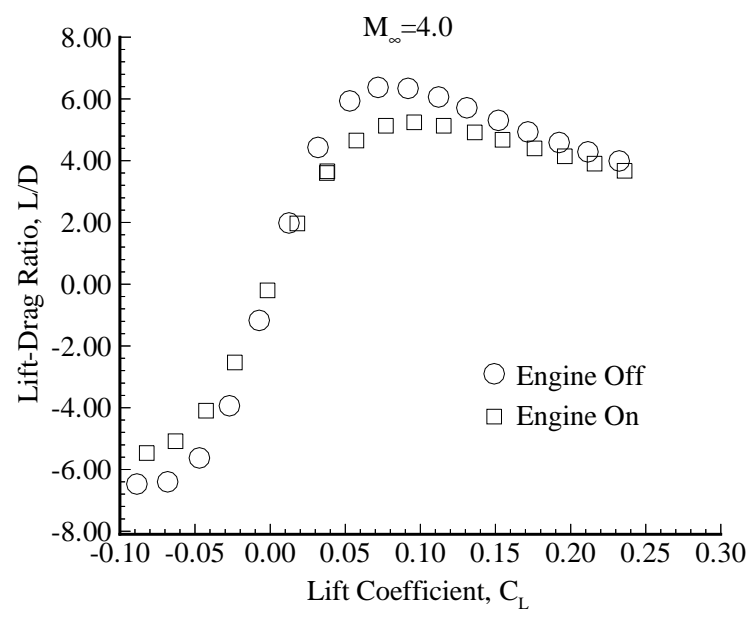

Figure 13. Effect of engine components on lift-to-drag ratios of cranked-wing waverider at Mach 4.0.

tion in maximum lift-to-drag ratio at Mach 4.0 for the cranked-wing configuration and a reduction of 13.9 percent for the straight-wing configuration.

Several methods for minimizing the performance degradation caused by the closure of the blunt base are possible. Previous studies have examined the possibility of using blunt trailing edges on control surfaces as a means of enhancing the aerodynamic performance. ${ }^{12,13}$ Waveriders with thick bases will be difficult to integrate and will suffer from significant performance degradations when the aftbody is closed. Also, as noted previously, some loss of lift is caused by the expansion on the waverider lower surface and the severe closure angle of the elevons. A control surface design which minimizes or eliminates these effects would enhance the aerodynamic performance of the configuration. Maintaining the lower surface as a waverider stream surface all the way to the base, while designing the upper surface as a slight expansion surface would reduce the base thickness. Longer control surfaces would also reduce the closure angle.

\section{Fully-Integrated Configurations}

The aerodynamic performance of each of the fullyintegrated waverider-derived hypersonic cruise configurations is significantly degraded from that of the corresponding pure waverider shape. Maximum lift-to-drag ratios across the Mach number range studied are shown in figures 16 and 17 for the cranked-wing and straight-wing waverider configurations, respectively. Each figure shows a comparison of the pure waverider model with no vehicle components attached and the fully integrated model with the faceted canopy, engine components, $0^{\circ}$ control surfaces and a vertical tail attached. The maximum lift-to-drag ratios do not vary significantly across the Mach number range for either fully-integrated configuration. As indicated previously, much of the performance degradation observed results from aftbody closure and the addition of $0^{\circ}$ control surfaces. The difference in maximum lift-to-drag ratios increases as Mach number decreases because freestream pressure increases as Mach number decreases. The maximum lift-to-drag ratio of the cranked-wing fully-integrated model is 4.56 at Mach 4.0, 


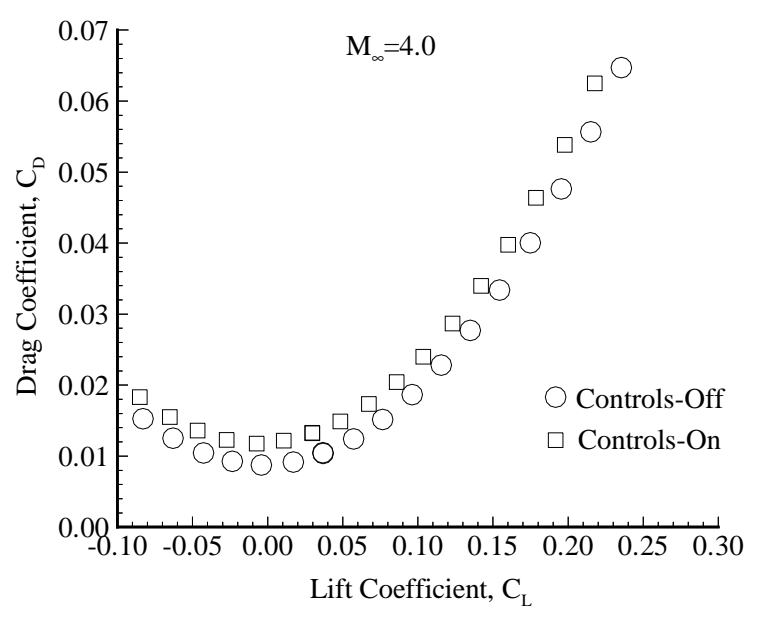

Figure 14. Effect of control surfaces on drag values of cranked-wing waverider at Mach 4.0.

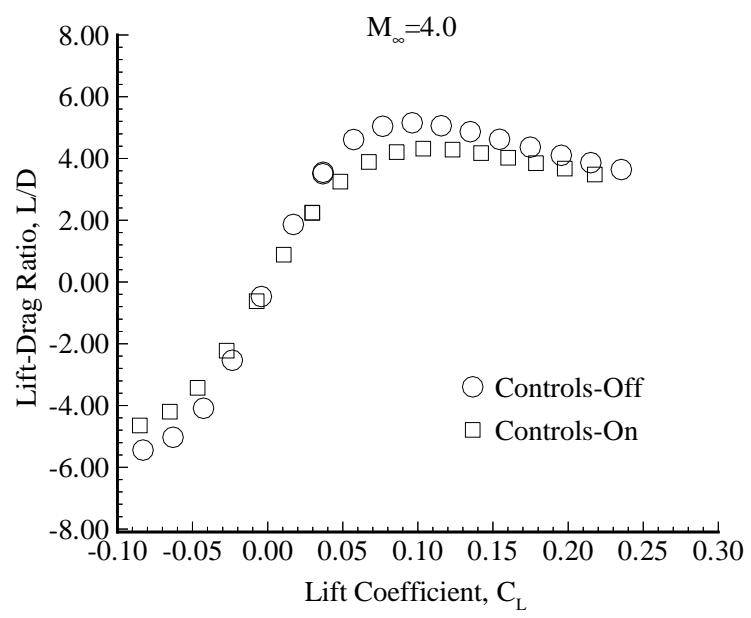

Figure 15. Effect of control surfaces on lift-to-drag ratios of cranked-wing waverider at Mach 4.0.

which corresponds to a 36.5 percent decrease when all vehicle components are added. The value for the straight-wing model is 4.69 , which corresponds to a 34.5 percent reduction.

The maximum lift-to-drag ratios measured here can be compared to the theoretical "L/D barrier" developed by Kuchemann, shown in figure $18 .^{2,4}$ The maximum lift-todrag ratios for the fully-integrated waverider vehicles are significantly lower than the L/D barrier shown. However, direct comparisons are difficult since the vehicles used to extrapolate this L/D barrier from theoretical and experimental data do not necessarily have the same volume or volumetric efficiency $\left(\mathrm{V}_{\mathrm{eff}}\right)$ as the waverider-derived vehicles. Additionally, if the waverider-derived vehicles were tested at flight-scaled conditions, the performance would be improved due a reduction in skin friction. The performance should also improve with the addition of a functioning propulsion system due to increased surface pressures on the aftbody surface. It is noted that no known vehicles have exceeded the L/D limit in figure 18. The lift-to-drag values for the waverider-derived vehicles studied here are similar to those of the B-58 and F-111, both of which had lower maximum Mach number capability. ${ }^{14}$

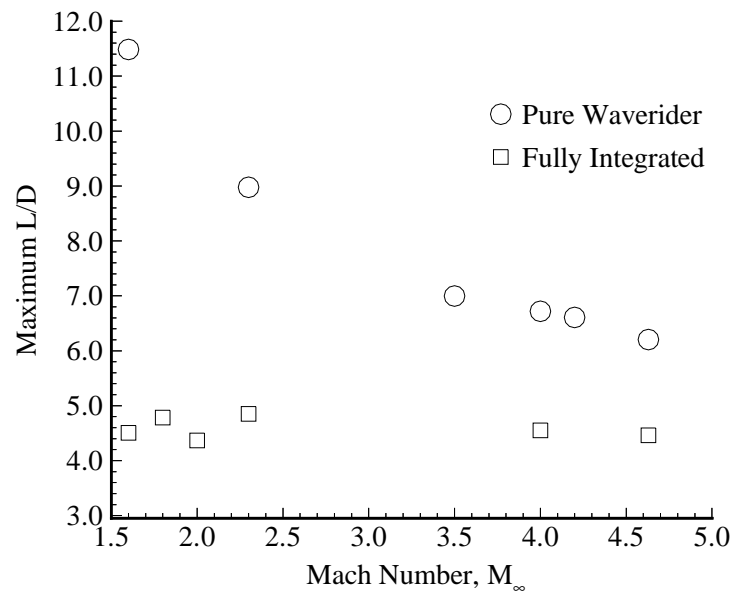

Figure 16. Comparison of maximum L/D values for the cranked-wing pure and fully-integrated configurations.

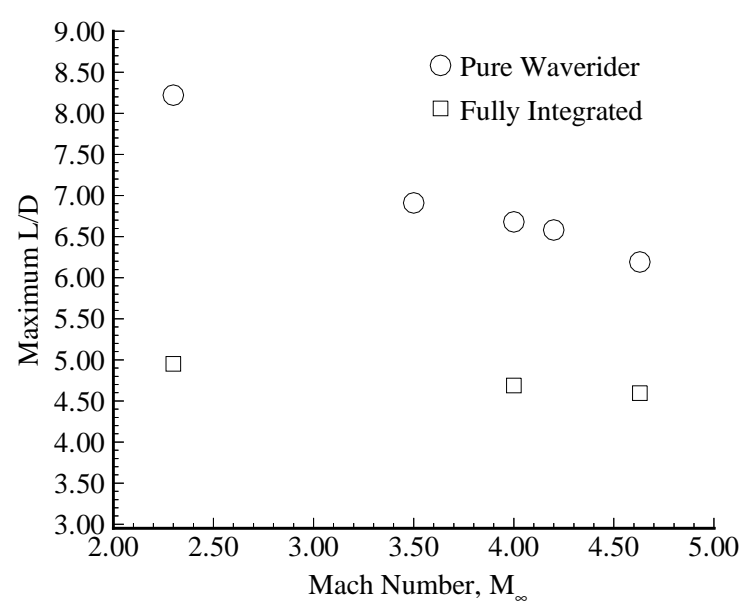

Figure 17. Comparison of maximum L/D values for the straight-wing pure and fully-integrated configurations.

Therefore, the configurations studied provide at least comparable aerodynamic performance to conventional supersonic/ hypersonic vehicles, even though the addition of vehicle components causes a significant degradation in performance. The waverider vehicles also still provide significant PAI advantages.

The pitching moment characteristics of each fullyintegrated configuration are shown in figure 19. Both configurations are longitudinally unstable using the moment reference center selected, which is 16.623 inches aft of the nose. However, this center of gravity location was arbitrarily selected and is not necessarily a desired flight location. A preliminary analysis indicates that the center of gravity shift with Mach number is acceptable and the location could be moved forward enough to provide at least neutral stability over the Mach number range. ${ }^{14}$ Also, the data presented are for unpowered conditions and the addition of a functioning propulsion system will enhance the longitudinal stability of these configurations due to the increased surface pressures on the aftbody caused by the exhaust stream. The pitching moment curve is non-linear for the cranked-wing model, indi- 


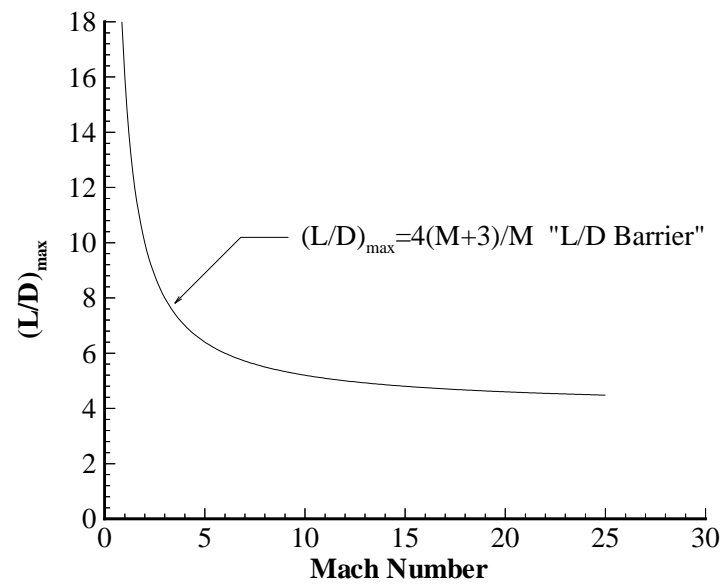

Figure 18. Theoretical L/D Barrier for supersonic and hypersonic configurations.

cating that the shock may be detached at higher Mach numbers for this configuration.

The lateral-directional stability characteristics of each fully-integrated configuration are shown in figures 20

and 21. Figure 20 shows yawing moment derivatives, $\frac{\partial C_{n}}{\partial \beta}$ at

Mach 4.0 for each model. Both configurations are directionally stable over the Mach number range studied. The addition of the vertical tail contributes significantly to directional stability. ${ }^{6}$ Rolling moment derivatives, $\frac{\partial \mathrm{C}_{1}}{\partial \beta}$, at Mach 4.0 are shown in figure 21 . The cranked-wing configuration is laterally stable over the Mach number range studied. However, the straight-wing model is unstable at angles of attack below $6^{\circ}$ at Mach 4.0. This instability may be caused in part by the high placement of the balance in the model. No transfer distance was applied in the vertical direction in the data reduction process. A preliminary analysis indicates that enough roll control power exists to overcome this instability. ${ }^{14}$

\section{Concluding Remarks}

The aerodynamic and controllability characteristics of two Mach 4.0 waverider-derived hypersonic cruise configurations were examined. Experimental force, moment and flow visualization data were obtained for two Mach 4.0 waverider planform shapes in both test sections of the Unitary Plan Wind Tunnel (UPWT) over a Mach number range of 1.6 to 4.63. The wind-tunnel model enabled testing of various configurations ranging from pure waveriders to fully-integrated vehicles. Limited computational solutions were obtained and used to examine the flow field and aerodynamic characteristics of the two baseline waverider shapes. Component build-up effects and the aerodynamic characteristics of the fully-integrated hypersonic cruise vehicles were evaluated.

Computational predictions and laser vapor-screen photographs of the straight-wing and cranked-wing pure

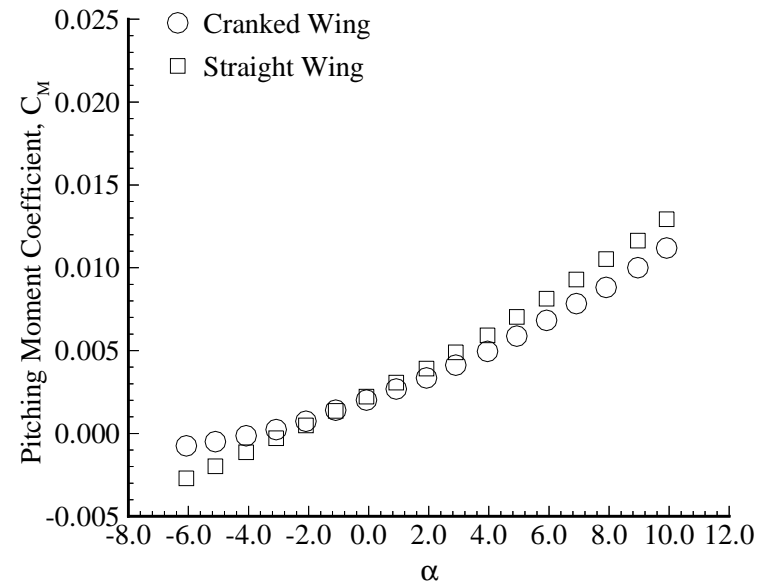

Figure 19. Pitching moment characteristics of each fullyintegrated configuration at Mach 4.0.

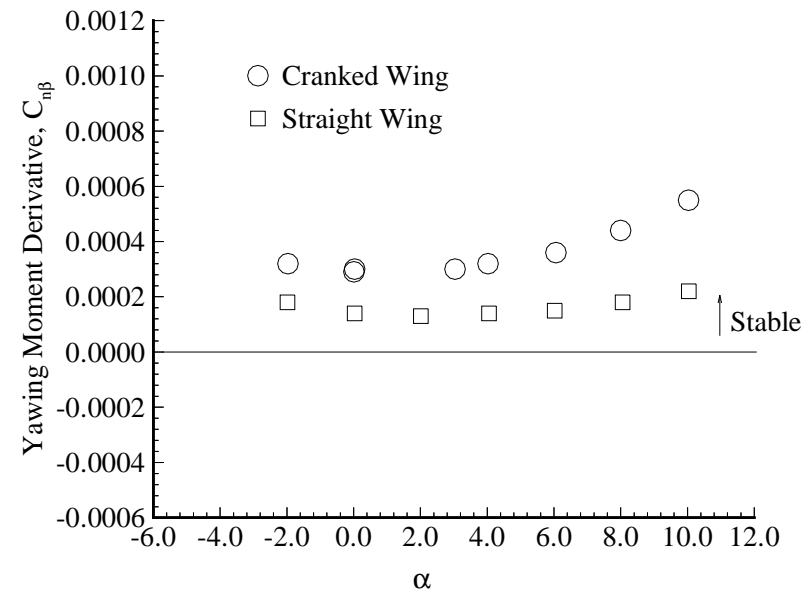

Figure 20. Yawing moment characteristics of each fullyintegrated configuration at Mach 4.0.

waverider configurations confirmed the qualitative shock locations for each configuration. The shock was slightly detached from the outer leading edge at the design Mach number of 4.0 and $0^{\circ}$ angle of attack. This detachment distance exists because of boundary layer displacement effects as well as blunt leading-edge effects. The design code assumes an infinitely sharp leading edge and does not account for the physical presence of a boundary layer. Comparisons between experimental force data and CFD predictions were generally good. The maximum lift-to-drag ratios observed experimentally were lower than the design-code predictions, as expected. This was due to a loss of lift and increase in drag caused by shock detachment as well as to a loss of lift from the lower-surface expansion and an increase in drag from the additional volume added to the upper surface.

The component build-up effects of waveriderderived vehicles were examined by comparing experimental force and moment data. The primary effect of adding the faceted canopy was to increase the drag of the configuration, thereby resulting in a slight degradation in aerodynamic performance. The effect of adding the engine package was to 


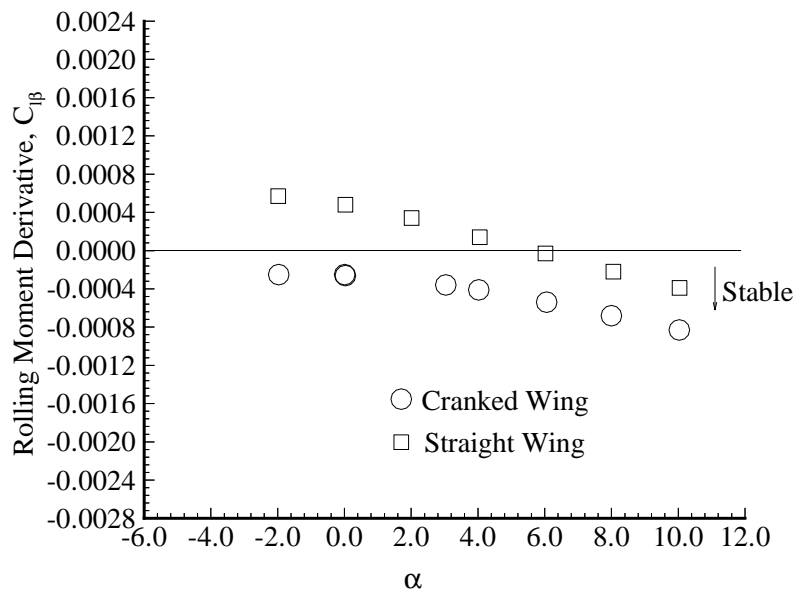

Figure 21. Rolling moment characteristics of each fullyintegrated configuration at Mach 4.0.

significantly increase the drag and degrade the aerodynamic performance. A slight increase in lift was also observed, caused by the inlet compression surface. The addition of control surfaces significantly degraded the aerodynamic performance of each configuration. Much of the performance degradation was caused by a large reduction in the base area when control surfaces were added to close the blunt base to a sharp trailing edge. The assumption of freestream pressure acting at the base was used for all data presented so that meaningful comparisons could be made between analytical, computational and experimental results. These results indicate that additional consideration should be applied to the design of control surfaces and aftbody closure in waveriderbased hypersonic cruise configurations. A control surface configuration with a less severe closure angle or controls with blunt trailing edges may result in improved performance. This implies that waveriders with smaller base areas may be better for integration into practical hypersonic vehicles.

The characteristics of the fully-integrated waverider-derived hypersonic cruise vehicles were also examined by comparisons of experimental force and moment data. The aerodynamic performance of both fully-integrated waverider vehicles was significantly degraded from that of the pure waverider shapes. However, the waverider concept still offers advantages in aerodynamic performance. The waverider concept also provides some advantages for airbreathing propulsion systems integration, specifically a uniform flow field entering the inlet. Furthermore, the results of this study have identified areas where design improvements could enhance the performance, such as control surfaces, aftbody closure and propulsion systems. Both fully-integrated vehicles are longitudinally unstable across the Mach number range studied with the selected reference moment center for unpowered conditions, but this instability is easily addressed. The cranked-wing configuration provides significantly better lateral-directional stability than the straight-wing configuration. The results of this study indicate that the waverider remains a candidate for a hypersonic cruise configuration.

\section{References}

1. Eggers, Alfred J. Jr. and Ashley, Holt. "Waverider Configurations from the 1950's to the 1990's," Proceedings of the First International Hypersonic Waverider Symposium, University of Maryland, College Park, MD, October 1990.

2. Bowcutt, Kevin G. and Anderson, John D. "Viscous Optimized Hypersonic Waveriders," AIAA Paper 87-0272, AIAA 24th Aerospace Sciences Meeting, Reno, NV, January 1987.

3. Corda, Stephen and Anderson John D. "Viscous Optimized Hypersonic Waveriders from Axisymmetric Flow Fields," AIAA Paper 88-0369, AIAA 26th Aerospace Sciences Meeting, Reno, NV, January 1988.

4. Kuchemann, D. The Aerodynamic Design of Aircraft, Pergamon Press, Oxford, 1978, pp. 1-22, pp. 448-510.

5. O’Neill, Mary Kae and Lewis, Mark D. "Optimized Scramjet Integration on a Waverider," Journal of Aircraft, vol. 29, no. 6, Nov.-Dec. 1992, pp. 1114-1121.

6. Cockrell, Charles E., Jr. Vehicle Integration Effects on Hypersonic Waveriders, Master of Science Thesis, George Washington University, Washington, DC, May 1994.

7. Jackson, Charlie M. Jr., Corlett, William A. and Monta, William J. Description and Calibration of the Unitary Plan Wind Tunnel, NASA TP 1905, November 1981.

8. Steinbrenner, John P. and Chawner, John R. The GRIDGEN Version 8 Multiple Block Grid Generation Software, MDA Engineering Report 92-01, MDA Engineering, Arlington, TX, May 1993.

9. McGrory, William D., Huebner, Lawrence D., Slack, David C. and Walters, Robert W. "Development and Application of GASP 2.0," AIAA Paper 92-5067, Fourth International Aerospace Planes Conference, December 1992.

10. McGrory, William D., Slack, David C., Applebaum, Michael P. and Walters, Robert W. GASP Version 2.2 User's Manual, Aerosoft, Inc., Blacksburg, VA, 1993.

11. Bowcutt, Kevin G., Weir, Jeff M., Myers, Glenn G. "Impact of Volumetric Constraints on Waverider Design and Performance," Rockwell International, Downey, CA.

12. Bushnell, Dennis M. "Supersonic Aircraft Drag Reduction," AIAA Paper 90-1596, AIAA 21st Fluid Dynamics, Plasma Dynamics and Lasers Conference, Seattle, WA, June 1990.

13. Chapman, Dean R. Reduction of Profile Drag at Supersonic Velocities By the Use of Airfoil Sections Having a Blunt Trailing Edge. NACA TN 3503, September 1956.

14. Finley, Dennis B., Dorsett, Ken and Robertson, Fred. Wind Tunnel Data Analysis of Mach 4.0 Waverider, Lockheed-Fort Worth Company Report, Fort Worth, TX, September 1993. 
